\title{
Non-enzymatic glycosylation in human diabetic lens crystallins
}

\author{
J. N. Liang ${ }^{1,2}$, L. L. Hershorin ${ }^{1}$ and L. T. Chylack, Jr. ${ }^{1,2}$ \\ ${ }^{1}$ Howe Laboratory of Ophthalmology, Massachusetts Eye and Ear Infirmary, and \\ ${ }^{2}$ Department of Ophthalmology, Harvard Medical School, Boston, Massachusetts, USA
}

\begin{abstract}
Summary. Lens crystallins undergo non-enzymatic glycosylation with aging and diabetes mellitus. It is not known, however, whether all crystallins are subject to the same extent of glycosylation. Human diabetic lenses ( $\sim 80$ years of age) were dissected into cortex and nucleus, then fractionated into various crystallins with gel chromatography (Sephacryl S-200, Sephdex G-75 or Bio Gel A-15m). The glycosylated crystallins were then separated from the nonglycosylated crystallins by affinity chromatography on Glyco Gel B boronic acid. The percentage of glycosylated crystallin was about $20-30 \%$, and did not differ much among most crystallins, although $\gamma$-crystallin has significantly less $(p<0.01)$ glycosylated protein. The
\end{abstract}

extent of glycosylation in the glycosylated crystallins, however, was found to be greater in the high molecular weight crystallins. The extent of glycosylation in $\alpha$-crystallins is approximately two to four times that observed in $\beta$-or $\gamma$-crystallin. The extent of glycosylation appears to depend not only on the lysine content, which does not vary much among the crystallins, but also on the accessibility of the surface areas where lysine residues are located. This accessibility depends on the protein conformation and appears to correlate with protein unfolding.

Key words: Crystallin, glycosylation, conformation, diabetes.
The human lens contains a very high content of proteins; most of them are represented by crystallins, the structural proteins. They are composed by three antigenically distinct families of polypeptide, called $\alpha-\beta$ and $\gamma$-crystallin. They undergo post-translational changes in the normal aging process, and appear to undergo changes to a greater extent in pathology.

The post-translational nonenzymatic glycosylation in haemoglobin and albumin has been suggested as a cause of changes in protein structures and functions leading to the pathogenic complications of diabetic mellitus [1]. The studies of glycosylation of lens proteins, however, have yielded controversial results [2-9]. Stevens et al. [2] suggested that glycosylation partially unfolds lens proteins and facilitates disulfide formation. However, Ansari et al. [5], although reporting an increased glycosylation of lens proteins of cataracts, found no correlation between glycosylation and disulfide bonding. A similar conclusion was reported by Pande et al. [4]. Stevens et al. [2] and Monnier et al. [3] also suggested that glycosylation plays a role in experimental sugar cataract formation, but such a role was disputed by Chiou et al. [7]. Despite these controversies, however, all studies concluded that more glycosylation occurs in lens proteins of senile and diabetic cataracts than in normal lenses.

Recently, Garlick et al. [10] studied the effect of glycosylation of human lens proteins changes on age and diabetes mellitus. They found that glycosylation increases with aging in non-diabetic lenses and is twofold higher than normal in diabetic lenses. They quantitatively reported results of the extent of glycosylation of both soluble and insoluble proteins of individual lens with aging and diabetes. They also identified lysine as the major site for glycosylation. The extremely slow rate of glycosylation in lens proteins, as compared to haemoglobin and albumin, appears to be regulated by a low concentration of glucose in the lens, a low content of lysine residue, and a unique protein conformation ( $\beta$-sheet conformation) that restricts molecular rotation.

Although glycosylation was measured in total soluble human lens proteins, it is not known whether the various protein fractions ( $\alpha$-, $\beta$ - and $\gamma$-crystallins) are equally glycosylated. In bovine lens proteins, Kabasawa and Kinoshita [11] reported that $\gamma$-crystallin had the highest level of bound sugars of the three crystallins. Chiou et al. [6] studied glycosylation in bovine lens crystallins by $\left[{ }^{3} \mathrm{H}\right] \mathrm{NaBH}_{4}$ incorporation and found that the amount of glucitol-lysine increased with age in all crystallins, with HMW $\alpha$-crystallin showing the greatest increase. In an earlier report, Stevens et al. [2] also showed an increased incorporation of ${ }^{14} \mathrm{C}$-labelled glucose into bovine crystallin, especially $\alpha$-crystallin, in experimental sugar cataract. In diabetic rat lenses, a similar increase in ${ }^{3} \mathrm{H}$ incorporation in $\alpha$-crystallin was observed [2].

It appears that the extent of glycosylation in a crystallin may depend on its lysine content. However, because of the supramolecular structure of protein, not all surface areas where lysine residues are located are ac- 
cessible to sugar molecules. All crystallins, except $\gamma-$ crystallin, exist in an aggregated state, with $\alpha$-crystallin showing the greatest extent. This tertiary or quaternary structural difference may affect the extent of glycosylation. Differences in tertiary structure as studied by spectroscopy have been reported among bovine lens crystallins [12-13]. Similar differences also exist among human lens crystallins [14], as the high sequence homology between the mammalian species would predict [15]. In this study, we have determined the extent of glycosylation in various crystallins isolated from diabetic lenses, and have tried to find a possible correlation to their protein conformation.

\section{Materials and methods}

Human lenses of diabetic patients ( $\sim 80$ years of age) were obtained from the National Diabetes Research Interchange (NDRI), Philadelphia, PA, USA. They were kept frozen prior to their use. Each lens was thawed, decapsulated and dissected into cortical and nuclear portions. Five to eight lenses were pooled together. Each pool was homogenized in $5 \mathrm{ml}$ of $0.01 \mathrm{~mol} / 1$ phosphate buffer, $\mathrm{pH}$ 7.6. The supernatants were applied to a column $(2.6 \times 100 \mathrm{~cm})$ of Sephacryl S-200 superfine gel (Pharmacia Chemicals, Uppsala, Sweden). All experiments were performed at $4{ }^{\circ} \mathrm{C}$. Detailed procedures for the lens protein isolation have been described elsewhere [13, 14, 16-18]. Six fractions were obtained, and they were rechromatographed on a smaller column $(1.0 \times 50 \mathrm{~cm})$ of Bio Gel A-15 m (fraction I), Sephacryl S-200 (fractions II- IV), or Sephadex G-75 (fractions V and VI) to minimize cross-contamination.

The separation of glycosylated crystallins was made on Glyco-Gel B boronic acid (Pierce Chemical, Rockland, IL, USA) [17, 19-20]. The separation was based on the interaction of the glyco moiety with boronate. Crystallins $(10-15 \mathrm{mg})$ in $0.25 \mathrm{~mol} / 1$ ammonium acetate buffer, $\mathrm{pH} 8.5$, were applied to a column $(3 \times 20 \mathrm{~cm})$ of Glyco Gel B. Nonglycosylated crystallin was eluted from the column with the starting buffer. The effluent was read at $280 \mathrm{~nm}$. When the reading reached less than 0.01 , the column was eluted with $0.2 \mathrm{~mol} / \mathrm{l}$ sorbitol in $0.25 \mathrm{~mol} / 1$ ammonium acetate, $\mathrm{pH} 8.5$. Each crystallin obtained from gel filtration was applied to the Glyco Gel B column and separated into glycosylated and non-glycosylated crystallins.

Glycosylation was estimated using the thiobarbituric acid (TBA) procedure of Flückiger and Winterhalter [21-22], based on the reaction of TBA with the released 5-hydroxymethylfurfural (5-HMF). Two $\mathrm{ml}$ of crystallin solutions were added to $1 \mathrm{ml}$ of $1 \mathrm{~mol} / \mathrm{l}$ oxalic acid and hydrolyzed at $100^{\circ} \mathrm{C}$ in a heating block for $4.5 \mathrm{~h}$. The hydrolysates were cooled on ice and $1 \mathrm{ml}$ of $40 \%$ trichloroacetic acid was added. The precipitates were filtered through $0.45 \mathrm{~mol} / 1$ filter. Aliquots $(2 \mathrm{ml})$ of the supernatants were incubated with thiobarbituric acid $(0.5 \mathrm{ml}, 0.05 \mathrm{~mol} / \mathrm{l})$ at $37^{\circ} \mathrm{C}$ for $30 \mathrm{~min}$. The absorbance at $443 \mathrm{~nm}$ was read. Reference curve using various concentration of 5-hydroxymethylfurfural (Aldrich Chemical, Milwaukee, WI, USA) was made for the estimation of the released 5-HMF. Samples of nonglycosylated crystallin were used to correct for nonspecific color development. Protein concentration was determined by the Lowry method [23].

Statistical analysis. For the statistical analysis, the $t$ value was first calculated; from the t value the probability level was determined from the table of the distribution of $t$.

\section{Results}

The fractionation of the soluble proteins on Sephacryl $\mathrm{S}-200$ gel has been described in previous papers $[18,24]$. Five main peaks and one small shoulder after the last peak were observed, corresponding to fractions I-VI. Fraction I was rechromatographed on Bio Gel A-15m column to separate the high and low molecular weight (HMW and LMW) $\alpha$-crystallin. Fraction I of the nucleus appears to be composed mainly of HMW $\alpha$-crystallin, the second peak on the Bio Gel A- $15 \mathrm{~m}$ elution profile being very small. This small amount of LMW $\alpha$-crystallin in the nucleus may be derived from the inner cortex. Roy and Spector [25] and Horwitz et al. [26] have reported that no LMW $\alpha$-crystallin was found in the core nucleus. Fractions II-IV were each rechromatographed on Sephacryl S-200 gel to minimize the cross-contamination. Fraction $\mathrm{V}$ was rechromatographed on Sephadex G-75 to remove the minor fractions [27-28]. Fraction VI was not further studied because of the low yield.

For the purpose of convenience, we used the conventional classification ( $\alpha$-, $\beta$ - and $\gamma$-crystallin). It has to be pointed out that this classification may not be ideal for diabetic cataracts, since many changes have occurred in proteins resulting from post-translational modification. Fraction I contains the HMW and LMW $\alpha$-crystallin. Fractions (II-IV) are $\beta_{1^{-}}, \beta_{2^{-}}$and $\beta_{3^{-} \text {-crys- }}$ tallin. Fraction $V$ is $\gamma$-crystallin, and based on the elution profile on Sephadex G-75, the major component is the $\gamma$-crystallin [27]. The last fraction (VI) is the 11,000 dalton protein [24].

The separation of the glycosylated crystallin from the nonglycosylated crystallin was achieved on Glyco Gel B boronate gel that binds vicinal hydroxyl groups of covalently linked sugar [19--20]. The binding appears to be specific, since the first fraction, which is nonglycosylated protein, gave only an insignificant reading in the TBA assay. This reading was used to correct in the assay for glycosylated crystallin. The percentage of each form was estimated by planimetry, assuming that both forms have the same absorbance at $280 \mathrm{~nm}$.

Percents of total protein glycosylated are listed in Table 1. They do not differ much among the crystallins, with the exception of the significantly less glycosylated $\gamma$-crystallin $(t=2.77,0.02<\mathrm{p}<0.01)$.

The extent of glycosylation as estimated by the TBA procedure is given in Table 2. It is expressed either as nmol of glucose per nmol of protein monomer, assuming the monomeric molecular weight of 20,000 , or as nmol of glucose per nmol of protein polymer, based on the previous reported molecular weights of 800,000 $\left(\alpha_{\mathrm{L}}\right) ; 140,000\left(\beta_{1}\right) ; 82,500\left(\beta_{2}\right) ; 39,600\left(\beta_{3}\right)$ and 17,000 $(\gamma)$ [24]. The figures are the total hexose released after hydrolysis, representing the actual extent of protein glycosylation. The calculation using polymeric molecular weight is included to show that the crystallins exist as polymers in the physiological state, and that the degree of glycosylation should be reflected under this condition.

\section{Discussion}

It has been reported that lens proteins (unfractionated) are more glycosylated in the cortex than in the nucleus [9]. Our results appear to agree with this observation for 
Table 1. Relative percentage of glycosylated crystallins in pooled human diabetic lenses ${ }^{\mathrm{a}}$

\begin{tabular}{lll}
\hline & $\begin{array}{l}\text { Cortex } \\
(\%)\end{array}$ & $\begin{array}{l}\text { Nucleus } \\
(\%)\end{array}$ \\
\hline$\alpha_{H}$ & $29 \pm 1$ & $19 \pm 1$ \\
$\alpha_{\mathrm{L}}$ & $19 \pm 3$ & $14 \pm 3$ \\
$\beta_{1}$ & $29 \pm 10$ & $32 \pm 11$ \\
$\beta_{2}$ & $29 \pm 5$ & $29 \pm 8$ \\
$\beta_{3}$ & $30 \pm 3$ & $14 \pm 5$ \\
$\gamma$ & $11 \pm 1$ & $9 \pm 1$ \\
\hline
\end{tabular}

a The values are the average of three experiments, and expressed as mean $\pm \mathrm{SD}$

Table 2. Extent of glycosylation in the glycosylated crystallins isolated from human diabetic lenses ${ }^{\mathrm{a}}$

\begin{tabular}{lcc}
\hline & Cortex & Nucleus \\
\hline$\alpha_{\mathrm{H}}$ & $0.150 \pm 0.011^{\mathrm{b}}$ & $0.094 \pm 0.012^{\mathrm{b}}$ \\
& $(--)^{\mathrm{c}}$ & $(-\cdots)^{\mathrm{c}}$ \\
$\alpha_{\mathrm{L}}$ & $0.127 \pm 0.012$ & $0.075 \pm 0.017$ \\
& $(5.06 \pm 0.49)$ & $(2.98 \pm 0.68)$ \\
$\beta_{1}$ & $0.053 \pm 0.008$ & $0.057 \pm 0.010$ \\
& $(0.37 \pm 0.06)$ & $(0.40 \pm 0.08)$ \\
$\beta_{2}$ & $0.034 \pm 0.012$ & $0.032 \pm 0.008$ \\
& $(0.14 \pm 0.05)$ & $(0.13 \pm 0.03)$ \\
$\beta_{3}$ & $0.033 \pm 0.010$ & $0.070 \pm 0.009$ \\
& $(0.066 \pm 0.019)$ & $(0.139 \pm 0.017)$ \\
$\gamma$ & $0.075 \pm 0.012$ & $0.042 \pm 0.009$ \\
& $(0.064 \pm 0.010)$ & $(0.036 \pm 0.007)$ \\
\hline
\end{tabular}

a Two pooled samples were measured; the values are their average expressed as mean $\pm \mathrm{SD}$;

${ }^{b}$ expressed in nmol per nmol of monomer, assuming the molecular weight of subunit polypeptide to be 20,000 ;

c expressed in nmol per nmol of polymer, based on the molecular weight of $\left(\alpha_{\mathrm{L}}\right) 800,000 ;\left(\beta_{1}\right) 140,000 ;\left(\beta_{2}\right) 82,500 ;\left(\beta_{3}\right) 39,600 ;(\gamma)$ $17,000(24)$. The molecular weight of $\alpha_{\mathrm{H}}$-crystallin is undertermined; the extent of glycosylation cannot be calculated in terms of polymeric form

most crystallins. The $\gamma$-crystallin and the $\beta_{3}$-crystallin of the nucleus, however, show a significant decrease in the amount of glycosylated protein. This may result from their decreased content with aging and cataract formation, as reported for the $\gamma$-crystallin [24, 29-31].

The extent of glycosylation of amino acids, mainly lysine residues [10], in glycosylated crystallins show a general decreasing order from the high molecular weight crystallins to the low molecular weight crystallins. Under an identical condition, the extent of glycosylation should be related directly to the lysine content in each crystallin. The amount of lysine residue in the LMW $\alpha$-crystallin has been reported to range from 4.8 to $5.2 \mathrm{~mol} \%$ [32-34]. In $\gamma$-crystallin the values ranged from $2.4 \%$ [28], to $2.9 \%$ [33] and 4.4\% [34]. The amino acid composition of $\beta$-crystallin has been reported for the second fraction of DEAE-cellulose chromatography and the lysine content is $4.1-4.5 \%$ [34]. No values have been reported for the individual $\beta$-crystallin. The HMW $\alpha$-crystallin isolated in this study is $\mathrm{HM}_{2}$ according to Harding [15], since we only used agarose gel filtration in the separation. It has been reported that this HMW $\alpha$ crystallin contains other crystallins and is partly crosslinked by disulfide bonds [15]. The lysine content was reported to be $4.0 \%$ [35]. The discrepancy between the lysine content and the extent of glycosylation aparently indicates that other factors also affect glycosylation.

One of the main factors is probably the protein conformation, i.e. the tertiary and quaternary structures. The secondary structure does not play a major role, since all crystallins have the same amount of $\beta$-sheet conformation [14]. The higher order of structures deal with the interacting properties and thus the aggregating property. The extent of glycosylation in this aspect will then depend on the accessible surface areas where lysine residues are located. This accessibility is enhanced when proteins become partially unfolded. A number of mechanisms have been proposed for the unfolding, including oxidation of tryptophan, oxidation of methionine, mixed disulfide formation with glutathione and glycosylation [15]. Spectroscopic studies on crystallins of both bovine [12] and human lenses [14] indicate that the susceptibility of tryptophan to oxidation is in the order of $\alpha>\beta>\gamma$. Therefore, it is possible that the more damage in $\alpha$-crystallin, which causes protein unfolding [36], may render it more susceptible to glycosylation. The conformational study indicates that HMW $\alpha$-crystallin has more exposed tryptophan than LMW $\alpha$-crystallin and the oxidation of tryptophan proceeded further [18]. Whether other posttranslational mechanisms also contribute to the difference in the extent of glycosylation is difficult to explore. However, it is possible that the initial glycosylation facilitated by tryptophan oxidation may further enhance the unfolding and thus the glycosylation, in view of the finding that in vitro glycosylation partially unfolds the protein [17].

The reactivity of lysine residue, i.e. its $\mathrm{pK}$ value, may also play a role in glycosylation. The $\mathrm{pK}$ value of lysine in proteins is about 10.0 , and can be altered by a change in the local charge environment. The slightly higher extent of glycosylation than expected in $\gamma$-crystallin may be due to the presence of free $\mathrm{NH}_{2}$ terminus. In haemoglobin, the free $\mathrm{NH}_{2}$ terminus was found to be a major site of glycosylation [20], because of their lower $\mathrm{pK}$ values.

Nonenzymatic glycosylation is a normal aging process, and is enhanced in diabetic patients. Its role in the pathogenesis of the complications of diabetes is not fully established [review, 1]. In vitro studies appear to indicate that glycosylation impairs the normal biological function of protein. For example, glycosylated serum albumin showed a partial loss in drug or other ligands (such as fatty acid) binding capability [37-38] and glycosylated collagen also showed a decrease in its crosslinking ability in fibril formation [39-40]. The present studies demonstrate that crystallins that tend to aggregate were more glycosylated. This finding, coupled with the evidence that the crystallins are more glycosylated in the diabetic lenses [10], suggests that glycosylation might induce a secondary change in protein. This in- 
cludes a conformational change, as shown by spectroscopic studies on $\alpha$-crystallin isolated from diabetic cataract [41].

Acknowledgement. Human lenses were obtained from National Diabetes Research Interchange (NDRI), Philadelphia, PA, USA. This work was supported by grants from the National Institute of Health (EY 4969) and the Brigham Surgical Group Foundation.

\section{References}

1. Kennedy L, Baynes JW (1984) Non-enzymatic glycosylation and the chronic complications of diabetes: an overview. Diabetologia 26: $93-98$

2. Stevens VJ, Rouzer CA, Monnier VM, Cerami A (1978) Diabetic cataract formation: potential role of glycosylation of lens crystallins. Proc Natl Acad Sci USA 75: 2918-2922

3. Monnier VM, Stevens VJ, Cerami A (1979) Nonenzymatic glycosylation, sulfhydryl oxidation and aggregation of lens proteins in experimental sugar cataracts. J Exp Med 150: 1098-1107

4. Pande A, Garner WH, Spector A (1979) Glycosylation of human lens protein and cataractogenesis. Biochem Biophys Res Commun 89: 1260-1266

5. Ansari NH, Awasthi YC, Srivastava SK (1980) Role of glycosylation in protein disulfide formation and cataractogenesis. Exp Eye Res 31:9-19

6. Chiou SH, Chylack Jr LT, Tung WH, Bunn HF (1981) Nonenzymatic glycosylation of bovine lens crystallins: Effect of aging. J Biol Chem 256: 5176-5180

7. Chiou SH, Chylack Jr LT, Bunn HF, Kinoshita JH (1980) Role of nonenzymatic glycosylation in experimental cataract formation. Biochem Biophys Res Commun 95: 894-901

8. Kasai KT, Nakamura N, Kase T, Hiraoka R, Suzuki F, Kogure F, Shimoda SI (1983) Increased glycosylation of proteins from cataractous lenses in diabetes. Diabetologia 25:36-38

9. Lee JH, Shin DH, Lupovitch A, Shi DX (1984) Glycosylation of lens proteins in senile and diabetes mellitus. Biochem Biophys Res Commun 123: 888-893

10. Garlick RL, Mazer JS, Chylack Jr LT, Tung WH, Bunn HF (1984) Nonenzymatic glycosylation of human lens crystallins: Effects of aging and diabetes mellitus. $J$ Clin Invest 74: 1742-1749

11. Kabasawa I, Kinoshita JH (1973) Carbohydrate associated with $\gamma$-crystallin of the calf lens. Exp Eye Res 16:143-150

12. Liang JN, Chakrabarti B (1982) Spectroscopic investigation of bovine lens crystallins. I. Circular dichrosim and instrinsic fluorescence. Biochemistry 21: 1847-1852

13. Andley UP, Liang JN, Chakrabarti B (1982) Spectroscopic investigation of bovine lens crystallins. II. Fluorescence probes for polar-apolar nature and sufhydryl group accessibility. Biochemistry 21: $1853-1858$

14. Liang JN, Andley UP, Chylack Jr LT (1985) Spectroscopic studies on human lens crystallins. Biochim Biophys Acta 832: 197-203

15. Harding JJ, Crabbe MJC (1984) The lens: development, proteins, metabolism and cataract. In: Davson H (ed) The eye, Vol IB. Academic press, New York, pp 207-492

16. Liang JN, Chakrabarti B (1981) Sugar-induced change in near UV circular dichroism of $\alpha$-crystallin. Biochem Biophys Res Commun 102: 180-189

17. Liang JN, Chylack Jr LT (1984) Changes in the protein tertiary structure with nonenzymatic glycosylation of calf $\alpha$-crystallin. Biochem Biophys Res Commun 123: 899-906

18. Liang JN, Chylack Jr LT (1985) Age-related change in protein conformation of normal human $\alpha$-crystallin. Lens Res 2 (3): 189-206

19. Mallia AK, Hermanson GT, Krohn RI, Fujimoto EK, Smith PK (1981) Preparation and use of a boronic acid affinity support for separation and quantitation of glycosylated hemoglobin. Anal Lett 14: 648-661.

20. Garlick RL, Mazer JS, Higgins PJ, Bunn HF (1983) Characterization of glycosylated hemoglobins. J Clin Invest 71: 1062-1072
21. Flückiger R, Winterhalter $\mathrm{KH}$ (1976) In vitro synthesis of hemoglobin $A_{1 c}$. FEBS Lett 71: 356-360

22. Winterhalter KH (1981) Determination of glycosylated hemoglobin. In: Kaplan NO, Colowick SP (eds) Methods enzymol, Vol 76. Academic Press, New York, pp 732-739

23. Lowry OH, Rosebrough NJ, Farr AL, Randall RJ (1951) Protein measurement with Folin phenol reagent. J Biol Chem 193: 265-275

24. Jedziniak JA, Baram H, Chylack Jr LT (1978) The molecular distribution, weight determination and concentration variation of the total water soluble proteins of human lens. Exp Eye Res 26: 377-388

25. Roy D, Spector A (1976) Absence of low-molecular-weight $\alpha$ crystallin in nuclear region of old human lenses. Proc Natl Acad Sci USA 73: 3484-3487

26. Horwitz J, Ding LL, Cheung CC (1983) The distribution of soluble crystallins in the nucleus of normal and cataractous human lenses. Lens Res 1: 159-174

27. Zigler JS, Horwitz J, Kinoshita JH (1981) Studies on the low molecular weight proteins of human lens. Exp Eye Res 32: 21-30

28. Kabasawa I, Kodama T, Kabasawa M, Sakaue E, Watanabe M, Kimura M (1982) Heterogeneity of human cataractous and normal lens $\gamma$-crystallins. Exp Eye Res 35:1-9

29. Lerman $S$ (1976) Lens fluorescence in aging and cataract formation. Doc Ophthal Proc Ser 8: 241-279

30. Ringens PJ, Hoenders HJ, Bloemendall H (1982) Protein distribution and characterization in the prenatal and postnatal human lens. Exp Eye Res 34: 815-823

31. Straatsma BR, Horwitz J, Takemoto LJ, Lightfoot DO, Ding LL (1984) Clinicobiochemical correlation in aging-related human cataract. Am J Ophthalmol 97: 457-469

32. Horwitz J (1976) Some properties of the low molecular weight $\alpha$ crystallin from normal human lens: Comparison with bovine lens. Exp Eye Res 23: 471-481

33. Dilley KJ, Harding JJ (1975) Changes in proteins of human lens in development and aging. Biochim Biophys Acta 386: 391-408

34. Coghlan SD, Augusteyn RC (1977) Changes in the distribution of proteins in the aging human lens. Exp Eye Res 25: 603-611

35. Dilley KJ (1975) The proportion of protein from the normal and cataractous human lens which exists as high molecular weight aggregate in vitro. Exp Eye Res 20: 73-78

36. Andley UP, Sutherland P, Liang JN, Chakrabarti B (1984) Changes in tertiary structure of calf-lens alpha-crystallin by nearUV irradiation: role of hydrogen peroxide. Photochem Photophys 40: 343-349

37. Poffenbarger PL, Megna AT (1980) Effects of glycosylation on function and metabolism of serum albumin. In: Srivastava SK (ed) Red blood cell and lens metabolism. Elsevier, New York, pp $485-488$

38. Shaklai N, Garlick RL, Bunn HF (1984) Nonenzymatic glycosylation of human albumin alter its conformation and function. $\mathbf{J}$ Biol Chem 259:3812-3817

39. Rosenberg H, Modrak JB, Hassing JM, Al-Turk WA, Stohs SJ (1979) Glycosylated collagen. Biochem Biophys Res Commun 91: 498-501

40. Li WY, Khatami M, Robertson GA, Shen SY, Rockey JH (1984) Nonenzymatic glycosylation of bovine retinal microvessel basement membrane in vitro. Invest Ophthalmol Vis Sci 25: 884-892

41. Liang JN, Hershorin LL, Andley UP, Chylack Jr LT (1985) The nonenzymatic glycosylation in human diabetic lens proteins and its induced change in conformation. Suppl Invest Ophthalmol Vis Sci 26: 51 (Abstract)

Received: 5 August 1985

and in revised form: 5 February 1986

Dr. J. N.Liang

Howe Laboratory

Massachusetts Eye and Ear Infirmary

Harvard Medical School

Boston, MA 02114

USA 